\title{
Impact of Vipassana Meditation on Life Satisfaction
}

\author{
Phra Taweepong Inwongsakul ${ }^{1}$, Sampathkumar ${ }^{2}$
}

\begin{abstract}
Vipassana Meditation is measured to be the embodiment of the tradition from 2500 years back. It is non-scientific technique of self-observation which leads to progressive improved insight and positive life satisfaction attributes, as also, inculcations of family, friends, school, living environment and self life-satisfaction. The goal of this research was to study the effectiveness of Vipassana meditation on life satisfaction. In this study 120 student participants (experimental and control) were selected. The experimental group was given Ten Days (ten hours per day and total hours taken was three hundred hours) Vipassana meditation course. After meditation course the Satisfaction with life scale was administered to experimental and control group immediately. The effect of intervention on experimental group was studied by comparing with control group in pre-post test phases. For analysis of data the GLM- Repeated measures of ANOVA was used. Findings indicate that Vipassana meditation had positive effect on the level of life satisfaction.
\end{abstract}

\section{Keywords: Vipassana Meditation, Life Satisfaction}

Vipassana is one of the India's ancient meditation technique also called as Mindfulness meditation. Long lost to humanity, it was rediscovered by Gautama Buddha more than 2,500 years ago (Andresen, 2000). Vipassana means to see things as they really are. It is a procedure of self-observation. The truth-realization by direct experience is the process of purification. This entire Path (Dhamma) is a universal remedy for universal problems and has nothing to do with any organized religion or sectarianism. For this reason, it can be practiced freely by all without conflict with race, caste or religion, in any place, at any time and will prove equally beneficial to one and all. Anderson (2000) says that with sustained practice, the meditation releases the tensions developed in everyday life and opens the knots tied by the old habit of reacting in an unbalanced way to pleasant and unpleasant situations, and develops positive creative energy for the betterment of the individual and society.

${ }^{1}$ Research scholar, Department of Studies in Psychology, University of Mysore, Mysore -570 006, Karnataka, India

${ }^{2}$ Assistant Professor, Department of Studies in Psychology, University of Mysore, Mysore -570 006, Karnataka, India. 
Vipassana is an appearance of mental training that will teach to experience the world in an entirely new way. Meditator learns what is truly happening to him, around and within him. It is a process of self-discovery, a participatory investigation in which he observes his own experiences while participating in them, and as they occur.

Vipassana meditation is unique in many ways. It is an ancient, free, nonprofessional, nonsectarian, ethical, universal, psychology of spiritual development. It is based upon methodical, continuous, objective observation of oneself at the level of sensations. This special form of observation catalyzes a multilevel, systems development throughout the strata of one's personality. Part of Vipassana unique contribution to mental health derives from its constellation of psychological actions. Vipassana induces changes at the molecular level of the meditator's body. It changes the biology of the meditator's body. It has a dramatic effect at the psychological level. Vipassana is also value-based education. It incorporates a cognitivebehavioral psychology that encourages active practice of ideal ways of solving problems, of interacting with others, or of participating in society. It is an environmental psychology that stresses the feedback loop of harmony. It is a path to nibbana, the transcendence of the material world. Finally, it is a unique tool of human growth, transformative from microstructure to illimitable expanse (Fleischman, 2005).

There are two main types of Buddhist meditation: Vipassana (insight) and Samatha (tranquility). The two are often combined or used one after the other (usually Vipassana follows Samatha). In China and Japan, an entire school of Buddhism developed around the practice of sitting meditation called Chan or Zen Buddhism. The present study focuses on only Vipassana Meditation and its effectiveness on Life-Satisfaction.

Life is complex and painful, a series of inner and outer conflicts. There must be an awareness of the mental and emotional attitudes which cause external and physical disturbances. To understand them one must have time for quiet reflection; to be aware of psychological states, there must be periods of quiet solitude, a withdrawal from the noise and bustle of daily life and its routine. This active stillness is essential not only for the well-being of the mind-heart but for the discovery of the real without which physical or moral well-being is of little significance. In this context the study aimed at investigating the effects of Vipassana Meditation on life satisfaction.

\section{Life Satisfaction}

Life satisfaction is the dominance of positive feelings to the negative ones in the daily life and means to be good in different views such as happiness and moral. Life satisfaction is referred as an assessment of the overall conditions of existence as derived from a comparison of one's aspiration to one's actual achievement. Life satisfaction involves generally the whole life of a person and all the aspects of life. 
Reis and Gable (2003) say that for most people, interpersonal relationship with lovers, family and good friends present the most authoritative sources of well-being and life satisfaction. Another relationship that produces happiness is contribution in religion and spiritual matters (Piedmont, 2004). In part this may reflect the fact that religiosity and prayer are related to higher hope (Snyder, 2004). Gainful employment also imported source of happiness (Argyle, 2001). Yet another important route to attaining a sense of contentment is through here-and-now contemplation of one's external and internal environment. Indeed, a common thread in Eastern thought is that immense pleasure is to be attained through being or experiencing. Even in Western societies, however, meditation upon internal experiences or thoughts has gained many followers (Shapiro, Schwartz, \& Santerr, 2002).

Meditation has been defined as a family of techniques which have in common a conscious attempt to focus attention in a non-analytic way and an attempt not to dwell on discursive, ruminating thought" (Shapiro, 1980). For example, Vipassana meditation (Langer, 2002) involves a nonjudgmental attention that allows a sense of peacefulness, serenity, and pleasure. Kabat-Zinn (1990) has posed the following seven qualities of Vipassana meditation: nonjudging, acceptance, openness, non-striving, patience, trust, and letting to. Likewise, in what is called concentrative meditation, awareness is restricted by focusing on a single thought or object such as a personal mantra, breath, word or even a sound (Carrington, 1998). Therefore, in the present study vipassana meditation is used to enhance the satisfaction of life.

\section{Rationale for the study}

A number of studies have reported the effect of Vipassana meditation on many psychological variables. Usha (2000) studied on effect of Vipassana meditation on physical and psychological level of college students. Kochargaonkar (2005) reports that Vipassana Meditation significantly affect the Subjective Well-Being of the adolescent.

Shapiro, Astin, Bishop and Cordova (2005) study that Vipassana meditation as a way of understanding and personal growth, influencing self-satisfaction. Meditation positively correlates with life satisfaction. The positive impact of Vipassana on various aspects of mental health and personality had been reported in the above studies and it was therefore expected that similar results would come in the present study. The level of satisfaction with life should be a key consideration for an individual contemplating the benefits of Vipassana Meditation.

The present day educational system more concentrates on classroom formal education rather than educational experience to the students. Educational system has the major responsibility to ensure psychosocial, physical and spiritual development of the individual and the society. Since the students of present generation are expected to be the leaders of the coming era. It is necessary to extend education to improve their life satisfaction that ensures individual growth towards better social and sustainable development. The purpose is to make students life better, to add a humanistic dimension to it, to help the inmates introspect and examine themselves and possibly understand the purpose of life better. Vipassana as a meditational technique is dedicated to fulfill these higher goals of life of students. It is believed that Vipassana has a great role to play in transforming socio-cultural misbehavior in student's life. Since Vipassana is believed to be a 
technique that facilitates deeper psychological introspection and to bring about long lasting behavioral changes, it was considered worthwhile to assess some of these changes in a scientific manner. Keeping in the view of existing literature the present study is planned to aim at introducing Vipassana meditation to enhance Life satisfaction among college students.

\section{METHOD}

\section{Objective}

To study the effect of vipassana meditation on life satisfaction.

\section{Hypothesis}

Vipassana Meditation enhances Life Satisfaction.

\section{Research Design}

Pre-Post experimental group design was used to study the effect of Vipassana Meditation on Life Satisfaction. The participants were assigned randomly in to two groups-Experimental and control groups. The Experimental group was exposed to Vipassana Meditation whereas the control group was no exposure. The participants of Experimental and control groups were tested on dependent variable before and after exposure.

\section{Participants}

The participants were inmate students from Mahajulalongkon Rajaviddayalaya University, Thailand. They have registered for Vipassana Meditation training course. A large group of participants were administered the scale. Only those selected for the study that have scored low level on life satisfaction. The total participant group consists of 120 students. Their age ranges between 18 to 24 years. Then the participants were assigned randomly into two groups namely experimental and control groups. For random assignment of participant in to the groups the random number table was used.

\begin{tabular}{llll}
\hline Gender & $\begin{array}{l}\text { Experimental } \\
\text { group }\end{array}$ & $\begin{array}{l}\text { Control } \\
\text { group }\end{array}$ & Total \\
\hline Boys & 30 & 30 & 60 \\
Girls & 30 & 30 & 60 \\
Total & 60 & 60 & 120 \\
\hline
\end{tabular}

\section{Measures}

1. Personal information schedule (PIS): This was developed by investigator and it includes identification data, socio-economic status, etc. 
2. Multidimensional Students Life Satisfaction Scale (MSLSS): This scale is developed by Scott Huebner in 2001. The 40-item MSLSS can be administered to Students in groups as well as individually. The MSLSS was designed to provide a profile of student's satisfaction with important, specific domains, namely Family, Friends, School, Living Environment and Self. Also assess their general overall life satisfaction. Higher scores indicate higher levels of life satisfaction. The reliabilities range from .70 to .90; thus they are acceptable for research purposes.

\section{Procedure}

Pre-test: A large group of participants were administered the life satisfaction scale. Only those were selected for the study who has scored low on life satisfaction. Then the participants were assigned into two groups randomly. For random assignment of groups the random number table was used. The experimental group consists of total 60 students who received Vipassana Meditation. The control group consists of total 60 students who do not received Vipassana Meditation training and kept into close observation.

\section{Intervention: The mechanism of Vipassana meditation}

Vipassana Meditation is new tool for correcting our behavior at all level of life. It has gain importance and remained popular as a tool for student's community and to able to make sense of what is happening to a person who is experiencing a mental disturbance. It is a way of selftransformation through self-observation. It focuses on the deep interconnection between mind and body, which can be experienced directly by disciplined attention to the physical sensations that form the life of the body, and that continuously interconnect and condition the life of the mind. It is this observation-based, self-exploratory journey to the common root of mind and body that dissolves mental impurity, resulting in a balanced mind full of love and compassion.

One month Vipassana meditation course was given to students of experimental group. The course was given to the students to practice ten hours per day and took three hundred total hours. The students must declare themselves willing to comply fully and for the duration of the course with the teacher's guidance and instruction that is, to observe the discipline and to meditate exactly as the teacher asks, without ignoring any part of the instructions, nor adding anything to them. This acceptance should be one of discrimination and understanding, not blind submission. Only with an attitude of trust can a student work diligently and thoroughly.

Investigator meets the students of experimental group. After initial interactions, day one activity was beginning with chanting of eight precepts. Then investigator gives all information regarding daily practice and code of conduct in the meditation hall, Information includes-daily time table, meditation technique, do and don'ts of meditation. The investigator is available to meet students privately between 12 to 1:00 p.m. Questions may also be asked in public between 9:00 and 9:30 p.m. in the meditation hall. The interview and question times are for clarifying the technique and for questions arising from the evening discourses for the interview can be on individual and group interview of the students. All students must observe Noble Silence from the beginning of the course until the morning of the last full day. Noble Silence means silence of body, speech, 
and mind. Any form of communication with fellow students, whether by gestures, sign language, written notes, etc., is prohibited.

To clarify the spirit behind the discipline and rules may be summarized as follows; Take great care that your actions do not disturb anyone. Take no notice of distractions caused by others. It may be said that a student cannot understand the practical reasons for one or several of the rules. Rather than allow negativity and doubt to develop, immediate clarification should be sought from the teacher. It is only by taking a disciplined approach and by making maximum effort that a student can fully grasp the practice and benefit from it. The emphasis during the course is on work. A golden rule is to meditate as if one were alone, with one's mind turned inward, ignoring any inconveniences and distractions that one may encounter. Finally, students should note that their progress in Vipassana depends solely on their own good qualities and personal development, and on five factors: earnest efforts, confidence, sincerity, health and wisdom.

\section{There are two stages of Vipassana Meditation}

1. Sitting Meditation: The meditator approaches a quiet place; sits comfortably, keeping his body straight and his head erect; closes his eyes and starts to meditate. If the meditator chooses Anapana Satipatthana the touch of air on one point of his nostril will be noted. Incoming breath will cause a sensation of on that point of the nostril; so also the outgoing breath, which will cause a sensation of touch on that same point of nostril. The meditator just focuses his mind on that sense of touch. If the meditator is following the instruction, the rise of his abdomen caused by incoming breath will be noted. Also the fall of his abdomen caused by the outgoing breath will noting. The mind of the meditator, while trying to concentrate on the rise and fall of the abdomen at all times, will wander outside his body a lot, too.

The meditator should note the rise of the abdomen. The next noting is on the fall of the abdomen, the third noting is on the sense of touch of his bottom on the seat (hardness). If the meditator finds that his mind is still wandering, the following second approach is recommended. The meditator should note the rise of the abdomen. The next noting is on the fall of the abdomen, the third noting will be on the manner of sitting, and then fourthly, on the sense of touch of his bottom on the mediator should disassociate his mind from the shape or the shape or the features of his body. He must note the sense of support (rigidity) in his body. If the mediator finds it too stressful to note four-steps, he should change to the change to the two-steps noting. When the mind wanders, he must note the wandering mind two to three times. He was find that the wandering mind ceases to exist at one of his noting.

2. Walking Meditation: For the meditator who aims to reach the Path and Fruition, it is very important to practice walking meditation. It contributes a lot to his sitting meditation, and as much to his general noting. One-Step Noting: When the meditator is moving his left foot, he notes "walking". When he is moving his right foot, he notes "walking" The shape and form of the foot must not be in the mind of the noting meditator. Shapes and forms are pannatti 
(conventional truths) only. When striving to find paramattha (absolute truth), the mediator must confine his awareness to the sense of movement only. Two-Steps Noting: When the meditator lifts his foot to move, he notes "lifting". The manner of movement of his foot upwards is to be noted. When the meditator puts his foot down, he notes "putting down". The manner of downward movement is the only interest of meditation to the meditator. Three-Steps Noting: When the meditator lifts his foot up, the manner of upward movement must be noted. When the foot moves forward, he notes the forward motion. Then he notes the gradual downward press of his foot to the ground. In Vipassana Meditation, conventional names and forms are not interest of noting. The meditator should try to see the manner of movement in terms of the four constituent elements (Dhatu) in all matter, namely: Pathavi-Dhatu (element of extension or earth elements), Apo-Dhatu (element of cohesion or water element), Tejo-Dhatu (element of kinetic energy or fire element), Vayo-Dhatu (element of support of motion, or wind element). When he lifts his right foot, he would notice that it becomes lighter and lighter as it goes up. That is the indication of the presence of the element of fire and the element of wind. When he puts his foot down to the ground, he would notice that it becomes heavier and heavier. That is the indication of the presence of the element of earth and the element of fluidity. Knowing the four constituent elements is a significant step for the mediator. Only then can he comprehend paramattha sacca. The essence of Vipassana Meditation is the ability of the meditator to be aware of all phenomena (1) as it is, and (2) when it happens. Six-steps Noting: The mediator notes the beginning of the lifting of his foot (heels). Next he notes the end of the lifting of his foot. Third he notes the beginning of the forward movement of his foot. Fourth he notes the end of the forward movement of his foot. Fifth he notes the beginning of the downward movement of his foot. If the mediator makes full use of his walking meditation time, in addition to his sitting meditation time, within the thirty days of his retreat. He will find that, because he desires to lift his foot, his foot starts to lift. Because he desires to put his foot down, the foot comes down. The summary of six notings: The desire (nama) arises first to cause the physical behavior (rupa) to happen. An alternative six-steps noting is as follows: The meditator notes the starting of the lifting of his foot. Then he notes that he lifts his foot. Third he notes that his is moving forward. Fourth he notes that his foot is going down. Fifth he notes that the foot is touching the ground. Sixth he notices the whole of his weight on that foot, so as to start lifting the other foot. This approach is good for young people who have a lot of wandering thoughts. If the mediator really can work as suggested, adhering to all the nothings in walking meditation, he is sure to find the Path and the Fruition very quickly.

Post-test: Satisfaction with life scale was administered for both experimental and control group immediately after the intervention. The effect of the intervention on experimental group was studied and compared in pre-post test phases. Later the same intervention activities were conducted to the control group also for ethical considerations.

\section{Data Analysis}

In order to test the hypotheses, a computer based SPSS package was used to analyze the data. The " $t$ " test was used to equate the groups and General Linear Model- repeated measures of 
ANOVA were utilized to find out the significance of variance within-subjects group effects and between-subjects group effects.

\section{RESULTS AND DISCUSSION}

Table No.1

Mean, SD and t values for pre-test and post-test scores on Total life satisfaction of boys and girls of both experimental and control groups.

\begin{tabular}{lllllll}
\hline GROUP & GENDER & \multicolumn{2}{l}{ PRE TEST } & \multicolumn{2}{l}{ POST TEST } & CHANGE \\
& & MEAN & SD & MEAN & SD & \\
\hline Experimental & Boys & 86.33 & 4.611 & 122.90 & 6.583 & 36.57 \\
& Girls & 86.77 & 6.942 & 119.87 & 3.785 & 33.10 \\
& Total & 86.55 & 5.847 & 121.38 & 5.539 & 34.83 \\
Control & Boys & 86.30 & 4.340 & 88.90 & 4.037 & 2.6 \\
& Girls & 86.07 & 4.863 & 85.77 & 6.606 & 0.3 \\
& Total & 86.18 & 4.571 & 87.33 & 5.653 & 1.15 \\
Total & Boys & 86.32 & 4.440 & 105.90 & 17.978 & 19.58 \\
& Girls & 86.42 & 5.953 & 102.82 & 18.003 & 16.40 \\
& Total & 86.37 & 5.229 & 104.36 & 17.982 & 17.99 \\
\hline
\end{tabular}

Table No.2

Summary results of GLM repeated measures ANOVA within and between subjects of Life satisfaction of boys and girls both experimental and control groups in pre test and post test situation.

\begin{tabular}{|c|c|c|c|c|c|}
\hline \multicolumn{6}{|l|}{ Within Subject Effects } \\
\hline SOURCE OF VARIANCE & SUM & OF & MEAN & $\mathrm{F}$ & $\mathrm{P}$ \\
\hline & SQUARES & & SQUARES & & \\
\hline Change pre $\&$ post test & 19422.004 & & 19422.004 & 701.902 & .000 \\
\hline $\begin{array}{l}\text { Change Expt and Control } \\
\text { group }\end{array}$ & 17018.504 & & 17018.504 & 615.040 & .000 \\
\hline Change Gender & 152.004 & & 152.004 & 5.493 & .021 \\
\hline Interaction Expt-Control & 1.204 & & 1.204 & .044 & .835 \\
\hline Group and gender & & & & & \\
\hline Error (Change) & 3209.783 & & 27.671 & & \\
\hline \multicolumn{6}{|l|}{ Between Subject Effects } \\
\hline Expt - Control Groups & 17767.604 & & 17767.604 & 597.984 & .000 \\
\hline Gender & 133.504 & & 133.504 & 4.493 & .036 \\
\hline $\begin{array}{l}\text { Expt - Control Groups and } \\
\text { Gender }\end{array}$ & 2.204 & & 2.204 & .074 & .786 \\
\hline
\end{tabular}


Repeated Measures of ANOVA revealed a significant increase in life satisfaction scores from pre to post test situation irrespective of the groups. The F value 701.902 was found to be highly significant $(\mathrm{p}=.000)$. Irrespective of the groups in pre-test, the mean total life satisfaction score was 17.99 is increased from 86.37 with the increase of 104.36 scores which found to be significant. When increase in the life satisfaction scores with reference to groups are concerned again a significant ' $\mathrm{F}$ ' value was observed $(\mathrm{F}=615.040 ; \mathrm{p}=.000)$ indicating a differential increase for experimental and control groups. From mean values it is evident that experimental group had an increase of 34.83 scores (from 86.55 to 121.38), whereas control group had increase of only 1.15 scores (from 86.18 to 87.33 ). So the increase in the life satisfaction has basically in the experimental group which can be attributed to the effectiveness of Vipassana meditation. However the interactions between gender with respect to change in the scores and gender with respect to groups and change in scores were found to be non-significant.

In between-subjects effects between groups (irrespective of conditions) together significant difference was observed $(\mathrm{F}=597.984 ; \mathrm{p}=.000)$. However interaction between groups and gender was found to be non-significant.

Previous study is also report similar findings (Kochargaonkar, 2005; Shapiro, Astin, Bishop \& Cordova, 2005). This studies correlate positively to meditation with life satisfaction. The clinical studies also have found that Vipassana meditation reduces stress and cultivates mindfulness, a nonjudgmental awareness of the present (Chiesa, \& Serretti, 2010; Germer, Siegel $\&$ Fulton, 2005). The vipassana meditator's performance also seems to increase life satisfaction, quality of life, self-esteem, self-concept and help the subjects to develop greater tolerance of common stressors in life. According to Chandiramani et al. (1995) Vipassana meditation emphasizes both conscious life style changes in the area of morality and deeper psychological analysis, which alters the contents and the processes of the mind in fundamental ways. Vipassana meditation courses had been found to bring out many positive changes in the behavior of jail inmates.

The present day educational system more concentrates on classroom formal education rather than educational experience to the students. Educational system has the major responsibility to ensure psychosocial, physical and spiritual development of the individual and the society. Since the students of present generation are expected to be the leaders of the coming era. It is necessary to extend education to improve their life satisfaction that ensures individual growth towards better social and sustainable development. The purpose is to make students life better, to add a humanistic dimension to it, to help the inmates introspect and examine themselves and possibly understand the purpose of life better. Vipassana as a meditational technique is dedicated to fulfill these higher goals of life of students. 


\section{CONCLUSIONS}

1. The Vipassana meditation has improved life satisfaction.

2. There is no difference between boys and girls in the rate of improvement on life satisfaction.

\section{REFERENCES}

Anderson, J. (2000). Meditation meets behavioral medicine: The story of experimental research on meditation. Journal of consciousness studies, 7, 17-73.

Argyle, M. (2001). The psychology of the happiness ( $2^{\text {nd }}$ Ed.). London: Routledge.

Carrington, P. (1998). The book of meditation. Boston: Element Books.

Chandiramani, K., Verma, S. K., \& Dhar, P. L. (1995). Psychological effects of Vipassana on Tihar Jail inmates. Vipassana Research Institute, Dhammagiri, Igatpuri: India,

Chiesa, A. A., \& Serretti, A. A. (2010). A systematic review of neurobiological and clinical features of mindfulness meditations. Psychological Medicine: A Journal of Research in Psychiatry and the Allied Sciences, 40(8), 1239-1252.

Fleischman, P. R. (2005). Vipassana Meditation: A Unique Contribution to Mental Health. Karma and Chaos, Vipassana Research Publications, www.pariyatti.com.

Germer, C. K., Siegel, R. D., \& Fulton, P. R. (2005). Mindfulness and psychotherapy. New York: Guilford Press.

Kabat-Zinn, J. (1990). Full catastrophe living. New York: Delacorte press.

Kochargaonkar, S. H. (2005). Effect of Vipassana on Subjective Well-Being and Academic Performance among Adolescents. Indian journal of Community Psychology.1 (2), pp.181-186

Langer, E. (2002). Well-being: Mindfulness versus positive evaluation. In C. R. Snyder \& S. J. Lopez (Eds.), Handbook of positive psychology (pp. 214-230). New York: Oxford University Press.

Piedmont, R. L. (2004). Spiritual transcendence as a predictor of psychosocial outcome from an outpatient substance abuse program. Psychology of Addictive Behaviours, 18, 213-222.

Reis, H. T., \& Gable, S. L. (2003). Toward a positive psychology of relationships. In C. L. Keyes \& J. Haidt (Eds.), Flourishing: The positive person and the good life (pp. 129 -159). Washington, DC: American Psychological Association.

Scott Huebner (2001). Multidimensional Students Life Satisfaction Scale. University of South Carolina Department of Psychology Columbia, SC 29208.

Shapiro, D. H. (1980). Meditation : Self-regulation strategy and altered state of consciousness. New York: Aldine.

Shapiro, S. L., Astin, J. A., Bishop, S. R., \& Cordova, M. (2005). Mindfulness-based stress reduction for health care professionals: Results from a randomized trial. International Journal of Stress Management, 12, 164-176.

Shapiro, S. L., Schwartz, G. E. R., \& Santerr, C. (2002). Meditation and positive psychology. In C.R. Snyder \& S. J. Lopez (Eds.) The handbook of positive psychology (pp. 632-645). New York: Oxford University Press.

Snyder, C. R. (2004). Hope and spirituality, International Society for Quality of Life Studies Conference, Philadelphia.

Usha, M. (2000). Vipassana: It is Relevance to the Individual and Society, Cited in Buddhism Today. Updated Online Document, http://www.vridhamma.org/Relevance-to-Individualand-Society-94 (Retrieved on 21st March, 2014). 